\title{
Aneurysmal Bone Cyst of the Spine
}

\author{
Wardan Almir Tamer* \\ Department of neurosurgery, Hama university, Syria
}

*Corresponding author: Wardan Almir Tamer, Head of Neurosurgery Department, National Hama Hospital, Hama, Syria

Submission: September 01, 2017; Published: November 13, 2017

\begin{abstract}
A 35yrs young patient, presented to the hospital with lower extremities neurological deficit, radiological investigation showed bony lesion in the posterior elements of $\mathrm{T}_{10}$ causing severe compression on the cord, emergency surgery was performed to decompress the spinal cord, the microscopic examination revealed that lesion was " aneurysmal bone cyst".
\end{abstract}

Keywords: Aneurysmal bone cyst; Thoracic spine; Lamina; Posterior spinal elements; Spinal cord

\section{Introduction}

Usually, the aneurysmal bone cysts which involve the spine are rare, they occur in 10-30\% of all aneurysmal bone lesions of the whole body. Although these lesions are generally regarded as nonneoplastic in nature, they are expansile tumors containing thinwalled, blood filled cystic cavities [1]. Occur most commonly in the thoracic and lumbar regions...in these cases the lesions generally arise in the posterior elements of the spine. And can expand and extend into the pedicles, vertebral body and spinal canal, resulting in pathological fracture and neurological deficit.

\section{Case Report}

Mr......NN a 35- year old man presented to our hospital with right leg pain and paresthesia, difficulty of walking. His compliance developed insidiously from 4 month ago, by mild right leg pain, which increased progressively; there is no back pain, no history of trauma. Physical examination revealed severe weakness in the dorsal flexion of the right foot, right Babinski sign, and increased tendon reflexes without clonus.

Radiological investigations revealed:

Normal lumbar x-ray, unclear changes in thoracic x-ray

Thoracic MRI with gadolinium: heterogeneous cystic lesion (ballooning appearance) involved the posterior elements (right lamina, pedicle, facet joint) of $\mathrm{T}_{10}$, narrowing of the spinal canal

With cord compression also noted (Figure 1-3)

MSCT scan was performed to help in the diagnosis as showen in (Figure 4-7).

The embolization of the aneurysm has been excluded from the management plane, because the spinal cord needed urgent surgical decompression. The patient sent to the OR for urgent spinal cord decompression surgery, complete $\mathrm{T}_{10}$ laminectomy with excision of the mass in the right lamina pedicle and $\mathrm{T}_{9}-\mathrm{T}_{10}$ facet joint was performed. Segmental T9-T10 fixation and fusion was done as showen in (Figure 8 \& 9)
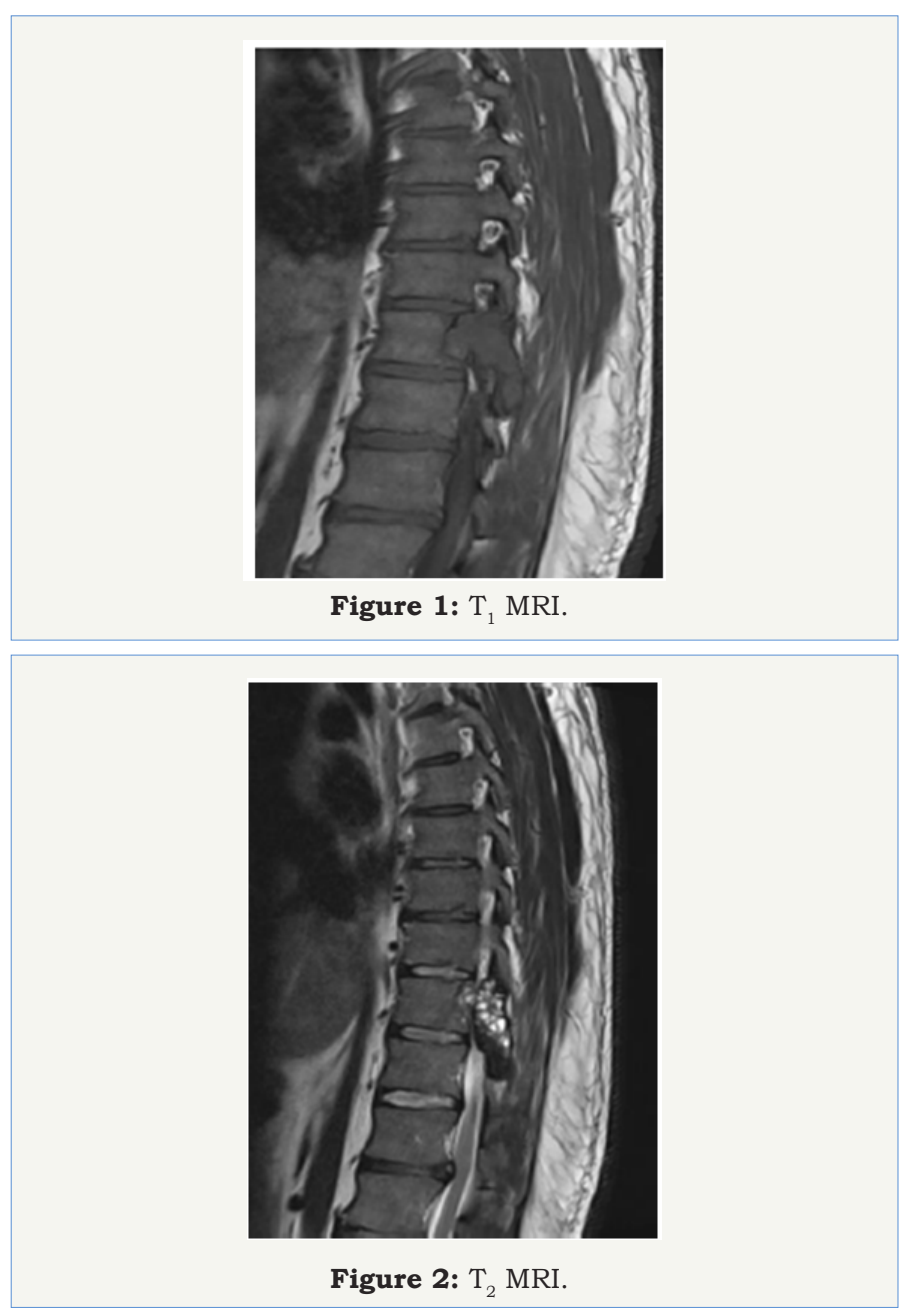


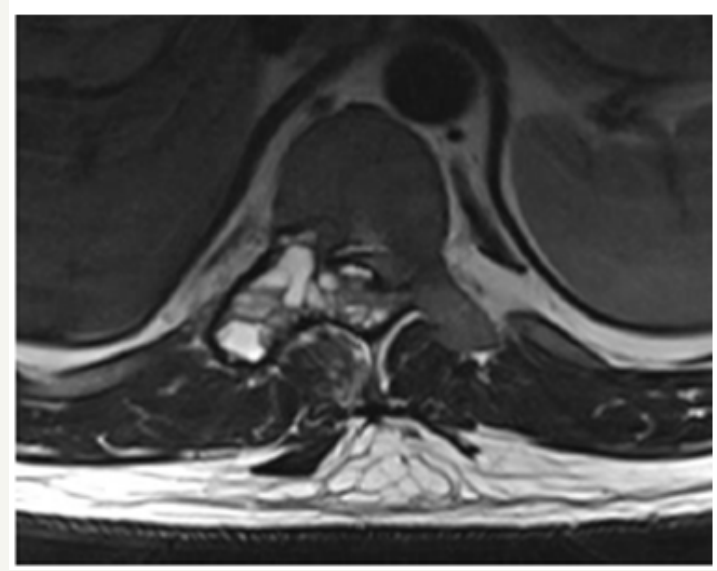

Figure 3: $\mathrm{T}_{2}$ axial view.

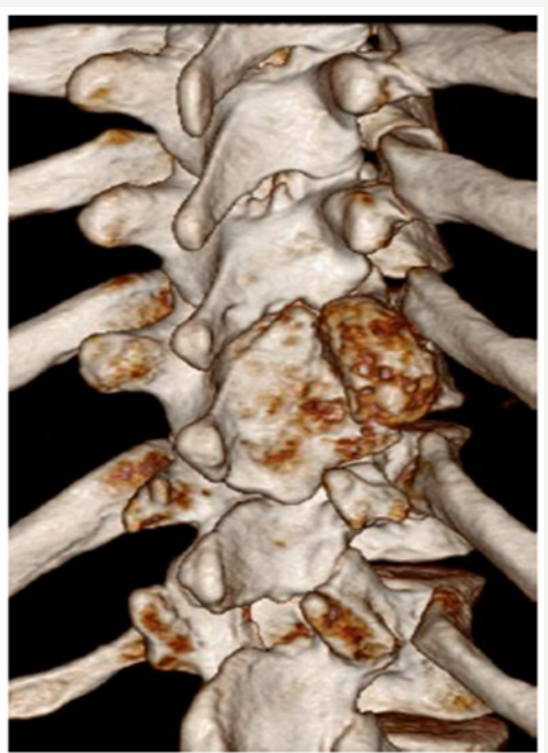

Figure 4

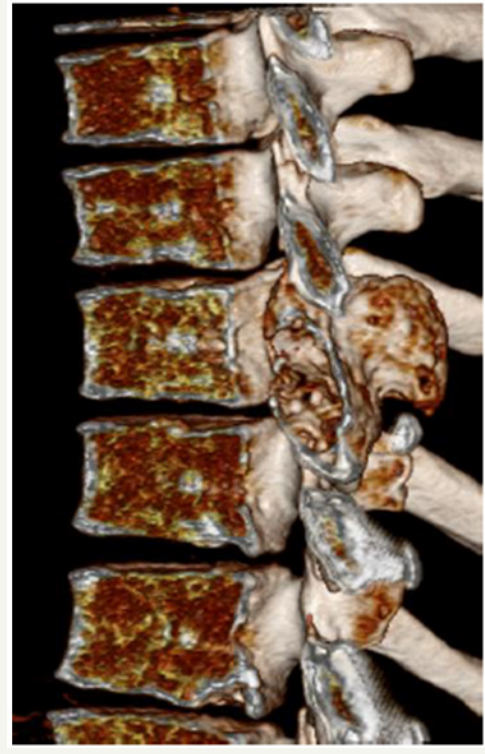

Figure 5

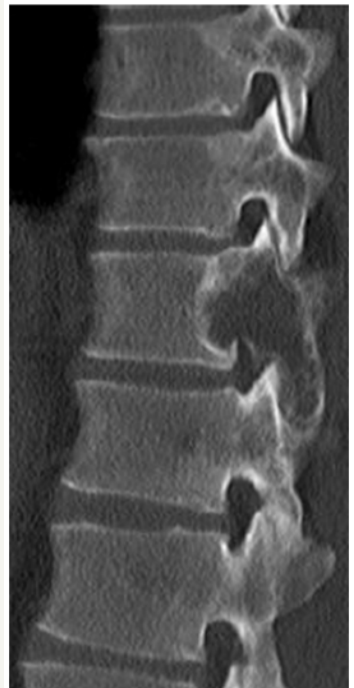

Figure 6

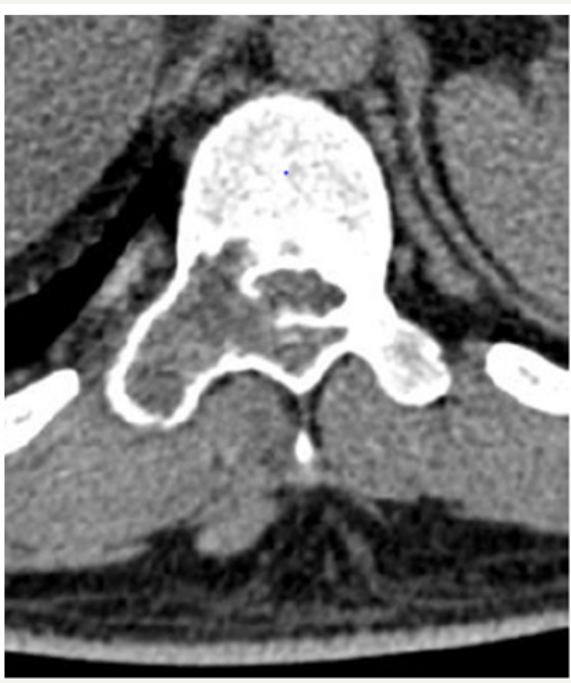

Figure 7

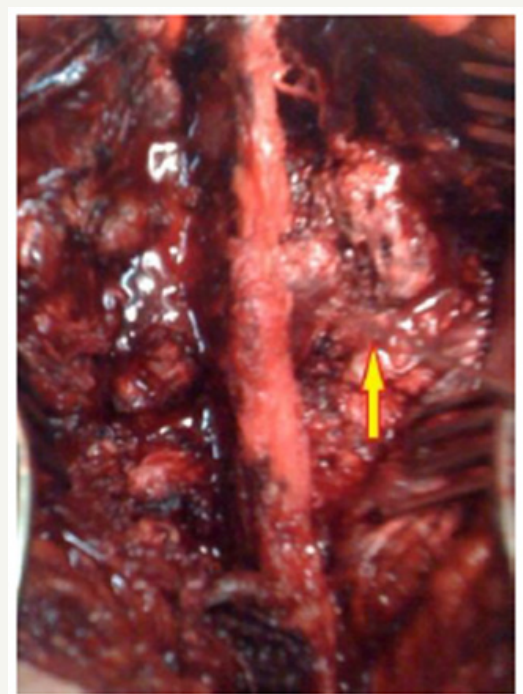

Figure 8 


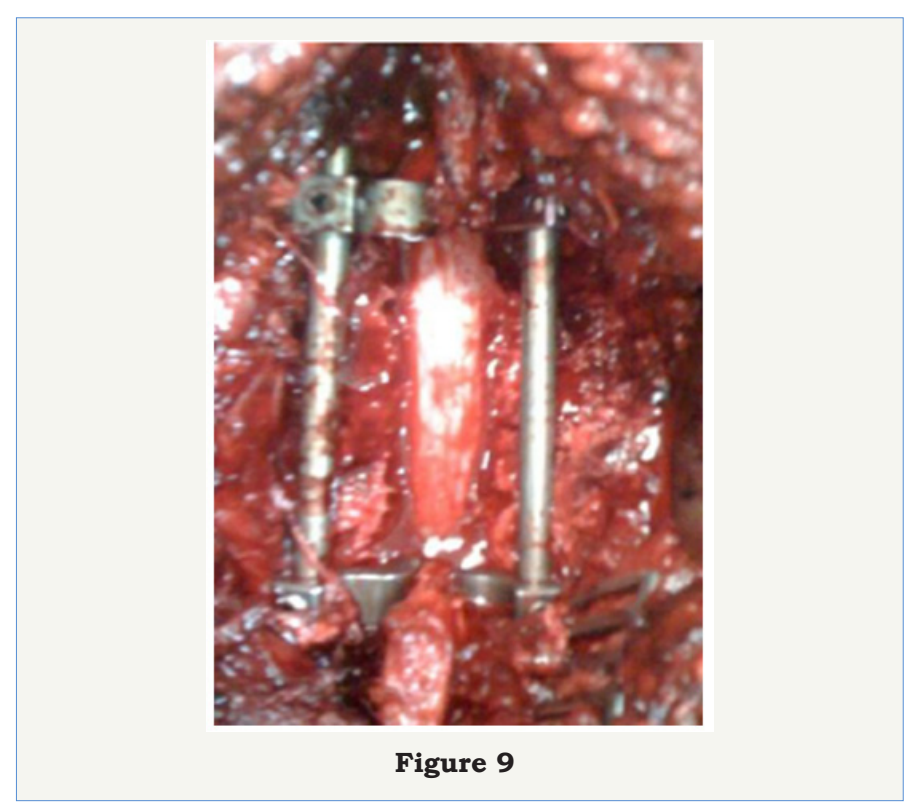

\section{Pathology}

Microscopic examination revealed proliferation of giant cells and polymorphic stromal cells, edging vascular spaces in part lined with endothelium .Fibrosis is noted, benign osseous tissue is present also.

\section{Discussion}

Comprehensive treatment of destructive lesion of the spine requires thorough preoperative assessment of the character and extent of bony compromise ,so that informed evaluation of effects upon spinal stability may be made, this type of preparation allows for adequate decompression of the neural elements without failure to recognize the potential danger of spinal instability. Involvement of the posterior elements with preservation of an eggshell thin margin of bone is a quite typical x-ray appearance for aneurysmal bone cysts of the spine. The benefit of combining excision of aneurysmal bone cysts of the spine with stabilization is allowing for aggressive excision of the lesion [2], a requirement for treating aneurysmal bone cyst, since subtotal resection is associated with a high incidence of recurrences that does not respond to radiation therapy, furthermore, radiation therapy in such cases has also been associated with sarcoma formation [3].

The usefulness of CT and MRI in planning the surgical management of destructive lesions of the spine and evaluating potential spinal instability is emphasized by the case presented.=

\section{Conclusion}

The surgical management of aneurysmal bone cyst of the spine remains a challenge, complete excision of the lesion offers the best chance of cure and neurological decompression, if deficits are present [4], preoperative evaluation by 3D CT and MRI is of benefit, if instability is anticipated, fixation and fusion are necessary. No rule of embolization, if the patient has neurological deficit [5].

\section{References}

1. Saccomanni B (2008) Aneurysmal bone cyst of spine: a review of literature. Arch Orthop Trauma Surg 128(10): 1145-1147.

2. Papagelopoulos PJ, Carrier BL, Shaughnessy WJ, Sim FH, Ebsersold MJ, et al. (1998) Aneurysmal bone cyst of the spine, Management and Outcome. Spine 23(5): $621-628$.

3. Frassica FJ, Frassica DA, World LE, Beabout JW, Sim FH, et al. (1993) Postradiation Sarcoma of Bone. Orthopedics 16(1): 105-109.

4. Rosman MA (1978) Aneurysmal bone cyst of the vertebra with paraplegia. Can J Surg 21(2):181-183.

5. Capanna R, Albisinni U, Picci P (1985) Aneurysmal bone cyst of the spine. J Bone Joint Surg 67(4): 527-531. 